Northern Ireland Kidney Research Fund; we thank Mrs Pat Watters, research assistant at the fund, for her help.

1 Branch RA, Clark GW, Cochrane AL, Jones JH, Scarborough H. Incidence of uraemia and requirements for maintenance haemodialysis. $\mathrm{Br} \mathrm{Med}$ $1971 ; \mathrm{i}: 249-54$.

McGeown MG. Chronic renal failure in Northern Ireland, 1968-70. Lancit 1972;i:307-10.
3 Pendreight DM, Heasman MA, Howitt LF, et al. Survey of chronic renal failure in Scotland. Lancet 1972;i:304-7.

+ Berlyne GM. The British dialysis tragedy revisited. Nephron 1985;41:305-6. Wood IT, Mallick NP, Wing AJ. Prediction of resources needed to achieve the national target for the treatment of renal failure. $\mathrm{Br}$ Med $\mathcal{F}$ 1987;294:1467-70.

6 Bergstrom J, Alvestrand A, Bucht H, Gutierrez A. Progression of chronic renal failure in man is retarded with more frequent clinical follow-up and better blood pressure control. Clin Nephrol 1986;25:1-6.

\title{
Delayed detection of congenital hearing loss in high risk infants
}

\author{
N J Wild, S Sheppard, R W Smithells, H Holzel, G Jones
}

\begin{abstract}
Objective-To examine the methods used to investigate children at high risk of congenital hearing impairment, and to see whether the introduction of evoked response audiometry has reduced the mean age at which hearing loss is identified.
\end{abstract}

Design-Clinicians who notified children to the national congenital rubella surveillance programme were asked retrospectively to complete a questionnaire examining the methods used to identify hearing impairment and the age at testing in two consecutive five year cohorts. The presence or absence of hearing loss was confirmed by obtaining the results of audiometric evaluations and, whenever possible, a recent pure tone audiogram.

Setting-The United Kingdom.

Patients-Children notified to the national congenital rubella surveillance programme and born in 1978-87 in whom IgM specific for rubella was detected shortly after birth.

Main outcome measures-The age at which hearing loss was identified and the degree of loss in decibels at 250, 500, 1000, 2000, and $4000 \mathrm{~Hz}$ measured by pure tone audiometry.

Results -61 (52\%) Of 117 children born in 1978-82 had a hearing impairment of $40 \mathrm{~dB}$ or greater in both ears. The mean loss was $93 \mathrm{~dB}$. In the following five years $75(47 \%)$ of 159 children had impaired hearing, their mean loss being $96 \mathrm{~dB}$. The age at which the hearing loss was confirmed decreased from 11.6 to 9.8 months as a result of earlier auditory evoked response testing. Nevertheless, only eight $(13 \%)$ of the children with hearing impairment born in 1978-82 and $16(21 \%)$ of those born in $1983-7$ had these tests performed in the first six months of life.

Conclusions-Unacceptable delays in identifying hearing loss occurred in this high risk group because of failure to arrange auditory evoked response testing in early infancy. Evoked response audiometry is sensitive and specific and should be undertaken within the first few months of life for all infants known to be at risk of sensorineural hearing loss

\section{Introduction}

The early detection of congenital sensorineural hearing loss in early infancy is important but difficult to accomplish. Children with congenital hearing impairment fall into two categories-those in whom there is no reason to anticipate hearing loss, and those

Br Med f 1990;301:903-5

TABLE I-Onset and severity of hearing loss

\begin{tabular}{|c|c|c|c|c|c|}
\hline & $\begin{array}{c}\text { No of } \\
\text { children }\end{array}$ & $\begin{array}{l}\text { No }(\%) \text { with } \\
\text { impaired hearing }\end{array}$ & Mean hearing loss $(\mathrm{dB})$ & $\begin{array}{l}\text { Mean age hearin } \\
\text { loss suspected } \\
\text { (months) }\end{array}$ & $\begin{array}{l}\text { Mean age hearing } \\
\text { loss confirmed } \\
\text { (months) }\end{array}$ \\
\hline Group 1 (1978-82) & 117 & $61(52)$ & $92 \cdot 1(\mathrm{R}), 94 \cdot 1(\mathrm{~L})(\mathrm{n}=54)$ & $7 \cdot 9(n=58)$ & $11 \cdot 6(n=58)$ \\
\hline Group $2(1983-7)$ & 159 & $75(47)$ & $95 \cdot 9(\mathrm{R}), 96 \cdot 3(\mathrm{~L})(\mathrm{n}=36)$ & $6.6(n=53)$ & $9 \cdot 8(n=72)$ \\
\hline
\end{tabular}

^Documented bilateral hearing loss of $40 \mathrm{~dB}$ or greater. in whom the family, prenatal, or perinatal history indicates a high risk. Children with a high risk may account for up to half of all cases. ${ }^{1}$ These children should have their hearing loss detected shortly after birth, which allows early treatment (including the provision of hearing aids when appropriate) and permits parental counselling and support.

The identification of sensorineural hearing loss has often been unacceptably delayed. ${ }^{23}$ With the increasing availability of equipment which allows accurate testing in early infancy this delay should have improved, certainly for high risk patients. We have determined the age of detection of sensorineural hearing loss in two consecutive five year cohorts of children at high risk as a result of congenital rubella infection. In addition to determining whether the introduction of new audiological techniques has led to earlier diagnosis, we have examined the causes of late identification of hearing loss.

\section{Patients and methods}

Children born in 1978-87 with congenital rubella confirmed by the detection of rubella specific IgM after birth were identified from the records of the national congenital rubella surveillance programme. The physician who notified each case was asked to provide details of the normality or otherwise of hearing and to supply the results of past hearing tests whenever possible. For those children with a hearing loss the ages at which it was suspected and confirmed were also obtained and a pure tone audiogram requested if appropriate.

\section{Results}

One hundred and seventeen children with congenital rubella confirmed by the detection of rubella specific IgM were born in 1978-82 (group 1) and 159 were born in 1983-7 (group 2). Table I shows the mean ages at which hearing loss was first suspected and confirmed in each group. Details of the hearing loss of affected children in group 1 have been reported. ${ }^{4}$ The hearing loss of those children in the second group who were old enough to cooperate with testing was remarkably similar to that in group 1 (table I). In the most recent audiograms the mean best point in the better ear was $76.0 \mathrm{~dB}$ in group 1 and $80.3 \mathrm{~dB}$ in group 2 . Only one child in each group had a documented progressive hearing loss.

Audiological examination with auditory evoked responses was infrequently undertaken during the first six months of life throughout the study. There was, however, an increase in the proportion of children with impaired hearing who had been tested by this age in group 2, and a substantial improvement in the numbers tested in the second six months of life also occurred (table II). Auditory evoked response testing seemed to be sensitive and specific-that is, no children were 
TABLE II-Age at first auditory evoked response test (children with hearing impairment only)

\begin{tabular}{lccc}
\hline & $\begin{array}{c}\text { No of } \\
\text { children }\end{array}$ & $\begin{array}{c}\text { No (\%) aged } \leqslant 5 \\
\text { months }\end{array}$ & $\begin{array}{c}\text { No(\%) aged 6-11 } \\
\text { months }\end{array}$ \\
\hline Group 1 (1978-82) & 61 & $\begin{array}{c}8(13) \\
16(21)\end{array}$ & $\begin{array}{c}2(3) \\
15(20)\end{array}$ \\
Group 2(1983-7) & 75 & &
\end{tabular}

misdiagnosed either as hearing impaired or as not affected.

Forty eight of the 75 children with hearing loss in group 2 were tested for evidence of congenital rubella because of a confirmed maternal infection, and the remainder were tested as a result of clinical findings after birth. Late identification of congenital rubella was uncommon and did not explain the delays in detecting hearing impairment. In 55 children with impaired hearing in group 2 rubella specific $\operatorname{Ig} M$ was detected within the first month of life. The diagnosis was suspected in early infancy in most of the other children in group 2 , and all but five had rubella specific IgM detected by 6 months of age.

Failure routinely to refer or late referral for audiological assessment was the main cause of delay in diagnosing hearing impairment (table III). In some cases this was compounded by long waiting lists and failure to attend clinics. Difficulty in obtaining an accurate assessment and malfunction of equipment also occasionally contributed. One child passed an auditory response cradle test and another a behavioural test in the neonatal period, and delayed diagnosis of hearing impairment resulted.

TABLE III -Causes of delayed assessment of hearing in 75 children in group 2 (born 1983-7) with impaired hearing

\begin{tabular}{lc}
\hline Routine referral not arranged & 22 \\
Referral too late for early diagnosis & 19 \\
Failure to attend a clinic & 6 \\
Delay in testing after referral & 5 \\
Equipment malfunction or testing difficulty & 4 \\
Passed a hearing test as newborn & 2 \\
Parents refused audiometry & 2 \\
Too ill to be tested & 1 \\
Not known & 5 \\
Tested in first six months & $20^{\star}$ \\
\hline Total & $86 \dagger$
\end{tabular}

* Sixteen tested for brain stem evoked responses, four tested by othe $\star$ Sixteen test
methods.

tTwo reasons given for seven children, three reasons given for two children.

\section{Discussion}

All the children in this study had congenital rubella and (apart from a few known to have been infected after the 20th week of pregnancy) a $50 \%$ risk of sensorineural hearing loss. Although the diagnosis was usually known shortly after birth, only a small proportion had been tested for auditory evoked responses by 6 months of age. For the few who had this type of test it was performed by their local audiological service and an accurate result obtained. For the remainder, who made up one of the highest risk groups for sensorineural hearing loss, the services seemed to have failed.

Although incontrovertible evidence that early diagnosis leads to improved linguistic outcome is difficult to obtain, at least one study has shown a benefit from early amplification for congenital sensorineural hearing loss. ${ }^{5}$ This is hardly surprising, given the weight of evidence showing the first year to be a critical period for speech development. ${ }^{6}$ As a result there has been an intensive effort to improve the reliability of screening and diagnostic tests for congenital hearing loss and acquired hearing loss of early onset. Auditory evoked response testing seems to be the best technique at present, although it is expensive and time consuming. ${ }^{7}$ Other, newer methods such as echocochleography are being evaluated and may prove useful. $^{8}$

As many children with moderate to severe hearing impairment have one or more risk factors one approach is to screen high risk children by using auditory evoked responses. Studies in North America suggest that half to three quarters of children with impaired hearing have one or more risk factors but that only one in 10 newborns are at risk. ${ }^{9-12}$ The American SpeechHearing-Language Association has suggested the following risk criteria ${ }^{13}$ :

(1) A family history of hearing impairment in childhood (excluding otitis media)

(2) Congenital infection - for example, with toxoplasma, other viruses, rubella, cytomegalovirus, and herpes virus (TORCH infections)

(3) Anatomical malformations of the head and neck (including dysmorphic appearance, cleft palate, and morphological abnormalities of the pinna)

(4) Low birth weight $(<1500 \mathrm{~g})$

(5) Hyperbilirubinaemia reaching exchange transfusion levels

(6) Bacterial meningitis

(7) Severe asphyxia (Apgar score $\mathbf{0 - 3}$ or failure to establish spontaneous respiration by 10 minutes).

Parental consanguinity, severe neonatal sepsis, extended stay in intensive care, and congenital hypothyroidism have also been identified as possible risk factors. In addition, several recent studies have shown that one fifth to half of all newborns with persistent fetal circulation have a hearing loss which may become apparent only in later infancy. ${ }^{14} 15$

We believe that a dramatic increase in the early detection of hearing impairment in early infancy is desirable and achievable. Initially this would best be accomplished by adopting a national policy of screening high risk infants along the lines suggested. In many cases newborn infants at high risk could be tested before leaving hospital, but adequate facilities for further investigation and management must be made available.

Health service personnel working with newborn babies and infants or their parents should be made aware of the risk criteria. Clear guidelines establishing responsibility for identifying high risk babies on the postnatal and neonatal wards should be laid down and implemented by each health authority. In addition to this neonatal screening procedure, the six week child health examination by general practitioners or clinical medical officers should include the use of a hearing checklist and a review of risk factors. ${ }^{16}$ Referral pathways which are well publicised and quick are crucial if screening along these lines is to be successful

Paediatricians in particular must arrange earlier referral of high risk patients, who should be tested before 3 months of age and provided with hearing aids, if required, before 6 months. It is not acceptable to "wait and see" whether a baby at high risk develops overt signs of hearing impairment.

We thank the medical personnel who provided information about the children in this study.

\footnotetext{
I Kramer SJ, Vertes DR, Condon M. Auditory brainstem responses and clinical follow-up of high-risk infants. Pediatrics 1989;83:385-92.

Coplan J. Deafness: ever heard of it? Delayed recognition of permanent hearing loss. Pediatrics 1987;79:206-13.

Martin JAM, Moore WJ. Childhood deafness in the European Community. Luxemburg: Commission of the European Communities, 1979.

Wild NJ, Sheppard S, Smithells RW, Holzel $H$, Jones G. Onset and severity of is $1280-3$.

5 Markides A. Age at fitting of hearing aids and speech intelligibility. Brf Audiol 1986;20:165-7.

6 McNeill D. The development of language. In: Mussen PH, ed. Carmichael's manual of child psychiatry. New York: John Wiley, 1970

7 Northern JL, Gerkin KP. New technology in infant hearing screening. Otolaryngol Clin North Am 1989;22:75-87.

8 Bonfils P, Uziel A, Pujol R. Screening for auditory dysfunction in infants b
} 
evoked oto-acoustic emissions. Arch Otolaryngol Head Neck Surg 1988:114 $887-90$

9 Jacobson JT, Morehouse CR. A comparison of auditory brain stem response and behavioural screening in high risk and normal newborn infants. Ear Hear 1984:5:247-53.

10 Mahoney TM, Eichwald JG. The ups and "downs" of high risk screening: the Utah statewide program. Seminars in Hearing 1987;8:155-63.

11 Stein L, Clark S, Kraus N. The hearing impaired infant: patterns of identification and habilitation. Ear Hear 1983;4:232-6.

12 Elssmann SF, Matkin ND, Sabo MP. Early identification of sensorineural hearing impairment. The Hearing fournal 1987;40:13-7.
13 American Speech-Hearing-Language Association. Guidelines for the identification of hearing impairment in at risk infants age birth to 6 months. ASHA 1988:30:61-4.

14 Hendricks-Munoz KD, Walton JP. Hearing loss in infants with persistent fetal circulation. Pediatrics 1988;81:650-6.

15 Naulty CM, Weiss IP, Herer GR. Progressive sensorineural hearing loss in survivors of persistent fetal circulation. Ear Hear 1986;7:74-7.

16 Hall DMB, ed. Screening for hearing impairment. In: Health for all children. Oxford: Oxford Medical Publications, 1989:59-67.

(Accepted 24 August 1990)

\section{Catheterisation: your urethra in their hands}

\author{
R Carter, M Aitchison, G R Mufti, R Scott
}

Department of Urology, Glasgow Royal Infirmary, Glasgow G4 OSF R Carter, FRCS, registrar M Aitchison, FRCS, senior registrar

G R Mufti, FRCS, consultant urologist

R Scott, FRCS, consultant urologist

Correspondence to: Mr Carter.

$\operatorname{BrMed~f~1990;301:90~}$ officers.
The emphasis in undergraduate medical education is often on the theoretical aspects of medicine rather than the practical aspects. Practical procedures are commonly taught informally, the teaching being passed from one junior to the next.' The philosophy is of "See one, do one, teach one." Urethral catheterisation is a procedure that requires a certain amount of skill, knowledge, and experience and is not without complication,,$^{2-4}$ yet it is usually delegated to the most junior and inexperienced medical staff, the junior house

\section{Subjects, methods, and results}

To assess the level of competence at catheterisation among junior medical staff house officers at this hospital were interviewed with a structured questionnaire, covering three aspects of the procedure: the degree of undergraduate and postgraduate instruction, the practical and theoretical aspects of catheterisation, and, finally, problems and complications encountered.

Thirty junior house officers (graduates of five medical schools) were interviewed. Eighteen were male and 12 were female. The replies to the questionnaire showed that none of the interviewees had received any formal instruction regarding any aspect of urethral catheterisation as an undergraduate. Practical postgraduate instruction in 24 was limited to supervision of a single catheterisation, and four subjects were unsupervised. Although those interviewed had performed a mean of 28 (range 6-100) catheterisations in male patients, only four of them had catheterised female patients.

Despite the large number of procedures performed there was appreciable ignorance of the practical and theoretical aspects of catheterisation. Twenty five interviewees were unaware of the availability of short term and long term catheters or of the duration for which they may be safely left without being changed. Three interviewees simply used the catheter that was provided by the nursing staff, and one did not know that different sizes existed.

Twenty eight interviewees initially used force when meeting resistance to the passage of the catheter, and 13 stated that the development of fresh urethral bleeding would not deter them from a further attempt at catheterisation. Eighteen were happy to attempt catheterisation in a patient who had a known urethral stricture. Five interviewees were unaware of the difference between a phimosis and paraphimosis.

Despite the lack of formal tuition all had developed what seemed to be a satisfactory aseptic technique. None, however, was aware of the nature of the antiseptic fluid or the strength of the local anaesthetic gel, but simply used what was provided by the nursing staff.

Nineteen of the interviewees had encountered bleeding and six had had patients in whom a paraphimosis had developed after catheterisation. A particularly disturbing finding was that, although 14 interviewees had requested help from senior medical staff, seven were reluctant to seek advice, because of their impression that difficulties with catheterisation were not worthy of disturbing senior staff. Eight of the 12 female medical staff had encountered problems with male patients becoming sexually excited during the procedure.

\section{Discussion}

The results of our survey suggest that the technique of urethral catheterisation is poorly taught, and in the light of these results we are preparing a short teaching video to be shown to every house officer at the start of their preregistration post.

1 Royal College of Physicians. Resuscitation from cardiopulmonary arrest. Training and organisation. London: RCP, 1987 .

2 Blandy JP. Emergency situations. Acute retention of urine. Br $\mathcal{F}$ Hosp Med 1987;19:109-11.

3 Merguerian PA, Erturk E, Hulbert WC, et al. Peritonitis and abdominal free air due to intraperitoneal bladder perforation associated with indwelling urethra catheter drainage. $\mathcal{F}$ Urol 1985;134:747-50.

4 Macfarlane DE. Prevention and treatment of catheter-associated urinary tract infections. F Infect 1985;10:96-106.

(Accepted 8 August 1990)

induce vaginal oestrus in laboratory animals ${ }^{4}$ in postmenopausal women not taking oestrogen replacement therapy.

$$
\text { II }
$$

\section{Subjects, methods, and results}

We studied 25 postmenopausal women who were non-smokers, in good general health, and taking no drugs known to affect oestrogen state (mean age 59 (range 51-70); body mass index $24 \cdot 4$ (range 18.7-31.6) $\mathrm{kg} / \mathrm{m}^{2}$; years after menopause $8 \cdot 1$ (range $\left.1-20\right)$ ). The protocol was a latin square design with a two week run in period and a six week experimental period. The women recorded their normal diet for 14 days and were asked to repeat the fortnightly diet throughout the study. During the experimental period the diet was oestrogenic activity ${ }^{1}$ and some foods contain potentic oestrogenic analogues such as the isoflavonoids (isoflavones and coumestans), lignans, and resorcyclic acid lactones, ${ }^{2}$ which may be activated or inactivated. We studied the effect of three foods reported to 